\title{
LOBO EM PELE DE CORDEIRO: \\ NOVAS ROUPAGENS E VELHAS ATITUDES NO ENSINO DE HISTÓRIA PROPOSTO PELA BNCC
}

\section{WOLF IN SHEEP'S CLOTHING: NEW CLOTHES AND OLD ATTITUDES IN HISTORY TEACHING PROPOSED BY BNCC}

Henrique Ferreira Pacini ${ }^{1}$

\begin{abstract}
RESUMO: O Ensino de História, proposto pelo Ministério da Educação, através da publicação para consulta da Base Nacional Comum Curricular (BNCC), tem suscitado um amplo debate na academia e nos meios escolares. O presente trabalho analisa o contexto político no qual a BNCC foi elaborada, tendo como parâmetros as questões propostas pelos Estudos Culturais, e as discussões teóricometodológicas elaboradas pelas recentes pesquisas em Ensino de História. Para tanto, a estrutura disciplinar e narrativa, bem como a posição teórico-metodológica dos autores, implícita na apresentação da disciplina História, constante na BNCC, foram analisadas. Conclui-se, a partir das análises, que apesar de alguns avanços pontuais na narrativa e nas formas de ensino propostas, a forma de Ensino de História manteve-se inalterada.
\end{abstract}

Palavras-chave: Ensino. História. Identidade. Base Nacional Comum Curricular. Consciência Histórica.

\begin{abstract}
The History of Education proposed by the Ministry of Education through the publication for consultation of the Brazilian National Common Curricular Base (BNCC) has sparked a broad debate in the academy and school environments. This paper analyzes the political context in which the BNCC was prepared, with the parameters of the questions posed by cultural studies and theoretical and methodological discussions drawn up by recent research in History Education. Therefore, the discipline and narrative structures as well as the theoretical and methodological position of its authors implicit in the presentation of the discipline History in BNCC were analyzed. We conclude from the analysis that despite some specific advances in storytelling and forms of education proposals, the way of history teaching has remained unchanged.
\end{abstract}

Keywords: Teaching. History. Identity. Brazilian National Common Curricular Base. Historical Consciousness.

\footnotetext{
${ }^{1}$ Professor do Ensino Fundamental II e Ensino Médio em colégios particulares e na Rede Municipal de Ensino de São Paulo. Doutorando da Faculdade de Educação da Universidade de São Paulo, tendo como área de concentração currículo e Didática da Histórica.
} 


\title{
Introdução
}

Dentre todas as disciplinas, o programa de História da proposta da Base Nacional Comum Curricular (doravante denominada aqui pela sigla BNCC), publicado em agosto de $2015^{2}$, foi o que suscitou o maior furor contestatório na academia e no meio educacional. As reações se deram, principalmente, devido aos conteúdos elencados para sua elaboração, pelas equipes formadas pelo Ministério da Educação. Às críticas levantadas contra os conteúdos, somam-se insatisfações relativas à metodologia didática da disciplina e à forma pela qual a discussão e implementação da BNCC foi planejada (MARTINS, 2015).

A presente análise pretende demonstrar que as concepções do Ensino de História, apresentadas na BNCC, remetem a questões de fundo relacionadas à construção da identidade cultural brasileira, e às diferentes posições políticoideológicas relativas a essa identidade, cujas implicações têm profunda influência em nosso cotidiano. Lautier (2011), a partir dos trabalhos de Chevallard, aponta a existência de um espaço difuso de influências sobre os conteúdos disciplinares a serem escolhidos para o ambiente escolar no processo de transposição didática. Esse espaço difuso, definido como noosfera, consiste na interferência que a política, os meios de comunicação, e as instituições diversas, exercem sobre a elaboração desses conteúdos. Nas palavras da autora

\begin{abstract}
As políticas e os meios de comunicação oferecem a cada dia exemplos facilmente identificáveis destas tentativas para influenciar a produção dos saberes ensinados (o dever de memória, o conhecimento reivindicado dos efeitos de um passado colonial, o dia nacional da abolição da escravidão...). Mais do que simples adaptação de um saber acadêmico disciplinar para colocálo a serviço dos profanos, os conhecimentos históricos ensinados precisam responder a múltiplos objetivos. (LAUTIER, 2011, p. 41).
\end{abstract}

Para analisar a polêmica, portanto, pretende-se realizar duas abordagens distintas e complementares sobre o assunto. A primeira delas, refere-se à construção político-ideológica da identidade cultural brasileira suscitada pelo programa de História da BNCC, tendo como parâmetro alguns conceitos forjados

20 presente artigo se refere à primeira versão da Base Nacional Comum Curricular (BNCC). 
pelos Estudos Culturais, como a noção de "pós-colonial" e "multiculturalismo". Tais conceitos serão aplicados ao contexto político e sociocultural brasileiro no qual a BNCC foi elaborada, a fim de trazer esclarecimento a respeito da noosfera que tem influenciado a sua criação. Importante mencionar que esse contexto tem implicações profundas no Ensino de História, principalmente no que tange à estrutura narrativa subjacente à proposta, cuja análise possibilita vislumbrar a maneira pela qual a disciplina é concebida pelos autores da BNCC, bem como seus objetivos e sua posição político-ideológica. A essa estrutura narrativa associam-se fatores que remetem à segunda estratégia de abordagem da questão, referente à própria Didática da História, enquanto metodologia e teoria do ensino dessa disciplina, cujas implicações determinarão a eficácia - ou o fracasso - do programa apresentado pela BNCC, no que tange aos objetivos propostos pelos seus idealizadores.

\section{A questão da identidade nacional}

Stuart Hall afirma que a identidade nacional é um parâmetro essencial para a estabilização e ação dos indivíduos dentro do tecido social. Através de sua construção é possível elaborar uma narração que abranja todos os indivíduos considerados como pertencentes a essa "história comum", estabelecendo um significado e dando-lhes um sentimento de pertencimento (HALL, 2006). Com o advento do Estado-nação no século XIX, várias narrativas surgiram com o objetivo de construir as identidades nacionais, principalmente aquelas elaboradas pelos historiadores. Elaboradas essas narrativas, as sociedades dos recémcriados Estados-nação justificaram suas organizações hierárquicas internas, e mesmo a dominação que exerceram sobre sociedades diferentes, como foi o caso do neocolonialismo.

No caso do Brasil, a construção da identidade nacional é tema que vem sendo abordado desde o período monárquico. Principal estratégia para a legitimação de sua independência política - uma "naturalização" de suas diferenças em relação a Portugal - a construção da identidade brasileira passou por significativas transformações em sua concepção, de acordo com as 
demandas sociopolíticas vigentes ao tempo de cada uma de suas formulações. Inicialmente formulada pelo Romantismo e, logo a seguir, de maneira científica pelo recém fundado Instituto Histórico e Geográfico Brasileiro, a elaboração identitária brasileira privilegiava a fusão das "raças" branca e indígena, desconsiderando os negros como parte de sua sociedade. Com o advento da abolição, os "pais" da Ciência Social Brasileira - Euclides da Cunha, Nina Rodrigues e Sílvio Romero - apropriaram-se de teorias raciológicas europeias, adaptando-as ao contexto brasileiro, e incorporando o negro à sociedade (ORTIZ, 2006). Infelizmente essa incorporação veio acompanhada de um monstruoso preconceito e valoração negativa do elemento negro na sociedade, o que pretensamente explicava o "atraso" brasileiro em relação à Europa, suscitando, assim, "acomodações" das teorias racistas, e gerando um projeto de "branqueamento" da população com vistas ao "desenvolvimento do país" (SKIDMORE, 1978).

Tal concepção, entretanto, era insuficiente para que se construísse um verdadeiro sentimento identitário nacional, por não integrar completamente uma grande parte da população brasileira. Essa integração vai ocorrer no contexto da centralização política e fortalecimento estatal do período Varguista (1930-1945), por meio da construção de uma ideia de nação que teve, na obra de Gilberto Freyre, Casa Grande e Senzala, uma justificativa política e cientificamente mais aceitável para superar o impasse identitário legado pelas teorias racialistas (SOUZA, 2015, p. 30). Partindo de uma visão culturalista e não mais racial, Freyre inverteu a forma pela qual a mestiçagem era vista no Brasil. De fator "debilitante" para o país, a mestiçagem passou a ser a principal, e mais positiva, característica do povo brasileiro, permitindo a incorporação de todos os indivíduos na narrativa do discurso identitário nacional. Narrativa esta que mascarava (e ainda mascara) as profundas desigualdades sociais, e raciais, pelas quais se caracteriza a sociedade brasileira, criando o "mito da democracia racial" no qual as relações raciais foram despidas de seu caráter opressor e violento, justificando um discurso ufanista e mantenedor de privilégios de raça e classe, ao naturalizar de maneira bastante sutil o domínio dos brancos sobre os povos indígenas e afro-brasileiros. 
Apesar das contestações teóricas iniciadas pelos trabalhos de Florestan Fernandes e de Thales de Azevedo, nas décadas de 1950 e 1960, e do próprio Movimento Negro, cujos estudos permitiram redimensionar a visão, até então hegemônica, sobre as relações raciais no Brasil, o mito da democracia racial ainda tem grande influência na maneira pela qual os brasileiros encaram sua própria identidade enquanto nação (GUIMARÃES, 2009; SOUZA, 2015). No caso da escola, o mito da democracia racial ainda perpassa, sem grandes constrangimentos, as aulas e os materiais didáticos de História do Brasil.

Entre os efeitos nefastos dessa situação, pode ser citado o racismo (não tão) disfarçado nas relações sociais e institucionais cotidianas, mascarado por um fantasioso ideal liberal e "meritocrático", cuja existência é legitimada pela falaciosa "democracia racial" (GUIMARÃES, 2009, p. 182). O ideal meritocrático pode ser observado, diariamente, nas escolas brasileiras, quando o assunto é cotas raciais. Quando indagados sobre o tema, a grande maioria dos (as) estudantes tende, inicialmente, a se posicionar contra as medidas, tendo por pressuposto que "todos são iguais no Brasil", sem avaliar o "grau de igualdade" realmente existente em nossa sociedade.

No caso das sociedades pós-coloniais ${ }^{3}$ como o Brasil, a estrutura de poder, alicerçada pela narrativa da identidade nacional, passou a ser contestada de maneira cada vez mais contundente, principalmente devido ao alargamento do debate público proporcionado pelas tecnologias da informação, como a internet, e pelo acesso dos movimentos sociais (negro ${ }^{4}$, feminista, LGBT, etc.) ao âmbito político. Maria da Glória Gohn, ao analisar as transformações nos movimentos sociais urbanos, e rurais, no Brasil nas décadas de 1970, 1980 e 1990, afirma

\footnotetext{
3 Hall explica o conceito de sociedade pós-colonial nos seguintes termos: "Problemas de dependência, subdesenvolvimento e marginalização, típicos do 'alto' período colonial, persistem no pós-colonial. Contudo, essas relações estão resumidas em uma nova configuração. No passado, eram articuladas como relações desiguais de poder e exploração entre as sociedades colonizadoras e as colonizadas. Atualmente, essas relações são deslocadas e reencenadas como lutas entre forças sociais nativas, como contradições internas e fontes de desestabilização no interior da sociedade descolonizada, ou entre ela e o sistema global como um todo" (HALL, 2013, p. 62).

4 De acordo com Petrônio Domingues, o Movimento Negro Unificado, criado em São Paulo, em 1978, a partir de várias associações negras, estabeleceu, em 1982, algumas metas de luta: "desmistificação da democracia racial brasileira; organização política da população negra; transformação do Movimento Negro em movimento de massas; formação de um amplo leque de alianças na luta contra o racismo e exploração do trabalhador; organização para enfrentar a violência policial; organização de sindicatos e partidos políticos; luta pela introdução da História da África e do Negro no Brasil nos currículos escolares, bem como a busca pelo apoio internacional contra o racismo no país". (DOMINGUES, 2007, p. 114).
} 
A relação da sociedade civil organizada com o Estado é de outra natureza nos anos 90, bem distinta dos confrontos nos anos do regime militar; ou das negociações, assembleias e consultas populares nos primeiros anos da Nova República. Hoje as arenas de negociação estão normatizadas e a institucionalidade da relação sociedade organizada-poder público é um fato. (GOHN, 2008, p. 318).

\section{A estrutura narrativa da BNCC}

\subsection{Pressupostos teórico-metodológicos de análise}

No contexto do presente trabalho, denomino 'estrutura narrativa' aquela forma de dar sentido à explicação histórica que foi apontada por Lautier (2011) ao analisar a forma pela qual os estudantes na França se apropriavam dos conteúdos de História. Fundamentando-se nos trabalhos de Ricoeur e Bruner, a pesquisadora francesa mostra que a forma de explicação da História se dá através do estabelecimento de uma sequência de fatos unidos através de relações causais cujos resultados são "mudanças no curso das coisas". Para essa autora, tanto estudantes quanto historiadores profissionais, de maneira mais ou menos semelhante, constroem seu entendimento da História a partir da construção de intrigas que dão sentido à narrativa histórica (LAUTIER, 2011). Será, portanto, na análise dessa intriga, subjacente ao conjunto dos conteúdos elencados pela BNCC, que buscaremos compreender sua estrutura narrativa.

Se levarmos em conta as questões levantadas pelos Estudos Culturais, relativos à identidade nacional e ao contexto no qual essas questões se colocam hoje no Brasil, podemos vislumbrar, com bastante acuidade, a intriga que subjaz à estrutura narrativa da História proposta pela BNCC. Para tanto, analisaremos as estruturas formal e discursiva do programa, a fim de buscar o sentido que seus elaboradores atribuíram à História.

\subsection{Estrutura formal geral do programa de História da BNCC}


A BNCC de História manteve a divisão por segmentos - Ensino Fundamental (10 ao 90 ano) e Ensino Médio. Os conteúdos, nomeados como "objetivos de aprendizagem", são elencados ano a ano, sendo estruturados a partir de quatro eixos temáticos:

1) Procedimentos de pesquisa;

2) Representações do tempo;

3) Categorias, noções e conceitos;

4) Dimensões político-cidadãs.

Os autores afirmam que "trata-se de uma tipologia para explicitar a operação predominante, mas não a única, em cada objetivo de aprendizagem" (BRASIL, 2015, p. 243). Dessa forma, um mesmo evento ou processo histórico é abordado a partir dessas quatro categorias que se complementam em cada ano da Educação Básica. Essa estrutura é justificada através da maneira pela qual os elaboradores da BNCC concebem as formas e finalidades do Ensino de História, na Educação Básica. Analisaremos esses aspectos com mais vagar na seção 3 . Por ora, basta apontarmos que o Ensino de História é concebido na BNCC como uma forma de proporcionar aos (às) educandos (as) a compreensão da nossa realidade política, socioeconômica e cultural através da pesquisa, com vistas a combater preconceitos enraizados em nossa sociedade e tendo por finalidade a construção de uma sociedade democrática.

Além dos quatro eixos temáticos expostos acima, a BNCC também se estrutura a partir de temáticas - denominadas "enfoques" - anuais. Pela sequência temática proposta, podemos perceber uma evolução na abrangência espacial da percepção dos fenômenos sociais que parte dos (as) educandos (as) - $1^{0}$ ano do Ensino Fundamental - até abranger a Humanidade - Ensino Médio. Dessa forma, nos anos iniciais do Ensino Fundamental parte-se do autoconhecimento social do (a) estudante, passando pelos grupos sociais dos quais faz parte, até abranger o município no qual vive. A partir do $5^{\circ}$ ano a temática nacional começa com toda a força até que, no Ensino Médio, as relações Brasil-Mundo são exploradas com maior destaque.

\subsection{Os anos iniciais do Ensino Fundamental}


A estrutura narrativa da História proposta pela BNCC tem início nos primeiros anos do Ensino Fundamental (do $1^{0}$ ao $5^{\circ}$ ano), priorizando, nos dizeres dos autores "[...] a construção das noções fundamentais do saber histórico", as quais são estabelecidas pelo documento como o manejo de "[...] fontes e documentos, noções do tempo, sujeitos, permanências e mudanças" (BRASIL, 2015, p. 241). Nessa fase, os objetivos de aprendizagem estabelecidos procuram proporcionar, aos/às educandos (as), a compreensão/construção de suas próprias identidades, e do grupo no qual estão inseridos (as), partindo do grupo familiar até abranger o país como um todo, no $5^{\circ}$ ano, no qual se estabelecem questões político-administrativas e geográficas na problematização da identidade nacional - mantendo o tradicional enfoque político para tratar do Brasil em sua totalidade. $05^{0}$ ano, portanto, aparece como uma fase de transição entre os fundamentos mais básicos da disciplina, marcados pelas histórias pessoais, e a narrativa histórica nacional, propriamente dita. 0 predomínio de conteúdos políticos, e não culturais, para iniciar essa transição, já aponta os limites que a construção de uma identidade nacional multicultural, através do ensino de História na escola implica, em um país cuja narrativa nacional foi, inicialmente, forjada após a realidade política estabelecida a partir da Independência.

\subsection{Os anos finais do Ensino Fundamental}

A segunda fase da narrativa histórica da BNCC compreende o Ensino Fundamental II - do $6^{\circ}$ ao $9^{\circ}$ ano -, na qual o enfoque passa a ser as relações entre os povos que formaram o Brasil - o indígena, o africano e o europeu. $\mathrm{Na}$ narrativa da BNCC essas relações são sempre conflituosas. Podemos perceber algumas permanências dos currículos anteriores, bastante familiares aos professores da Educação Básica, como a manutenção da narrativa histórica iniciada pela análise de cronologias, periodizações, calendários - com enfoque daqueles criados pelos povos americanos - e, logo em seguida, a abordagem da "Pré-história". No caso da periodização brasileira, proposta no $6^{\circ}$ ano, o fio 
condutor da narrativa é o político. Apesar da proposta, aparentemente, procurar fugir desse enfoque "estudando trajetórias de sujeitos, instituições e ideias, além de acontecimentos relativos às experiências política, econômica, social e cultural Brasileiras" (Objetivo de aprendizagem 073), apenas os acontecimentos relativos às formações políticas são especificados - "conhecer e problematizar as diferentes formas de organização política do Brasil, desde o período da colonização portuguesa até a contemporaneidade" (Objetivo de aprendizagem 074). (BRASIL, 2015, p. 250).

Nos anos finais do Ensino Fundamental, a narrativa histórica segue basicamente uma linha cronológica - que apresenta várias idas e vindas no tempo, mas que tem início no passado e desemboca, necessariamente, no presente - cujo sentido vai da colonização até a Nova República.

Os temas elencados, como exposto acima, foram adaptados para se adequar à narrativa maior proposta pelos autores. No 70 ano, cujo enfoque temático principal é "Processos e sujeitos", os autores focaram a questão da resistência à opressão. Os temas elencados são: Revoltas Nativistas e Crise do Sistema Colonial (Inconfidência Mineira e Revolta dos Alfaiates), Escravidão, abolicionismo e resistência. A proposta apresenta ainda alguns conteúdos relacionados aos povos ameríndios, os quais são pouco trabalhados pelos professores da Educação Básica atualmente, como a Revolta dos Manao e os movimentos indígenas.

No $8^{\circ}$ ano, cujo tema é "Análise dos processos históricos", o foco concentra-se nas relações de dominação, com ênfase nos processos que podem relacionar o Brasil e o mundo. Dessa forma, a proposta prevê o estudo das conformações político-econômicas de Portugal, dos Reinos Africanos, e das Américas, no contexto da expansão ultramarina. A partir daí, a proposta elenca a colonização do Brasil (Conquista da América, França Antártica e Guerra dos Tamoios, Tráfico Negreiro), o processo de Independência (Revolução Francesa e Independência da América espanhola), e os aspectos políticos do Império (10 e $2^{\circ}$ reinados e Regência) que se relacionam com a formação identitária nacional.

No 90 ano, a narrativa avança para o período republicano, enfocando processos históricos vividos no Brasil, relativos à economia e à política no século $\mathrm{XX}$, até processos históricos ocorridos em outros espaços e períodos" (Objetivo 
de Aprendizagem 123). Temas da República Velha (1889-1930) até a Nova República (a partir de 1985), são elencados pela proposta que mantém o foco na análise do binômio opressão-resistência (exploração dos seringueiros, movimento operário, o Golpe Militar de 1964, novo sindicalismo dos anos 19701980, movimentos sociais diversos, como o movimento negro, o feminismo, os movimentos indígenas e de adolescentes).

\subsection{O Ensino Médio}

No ensino Médio, os temas propostos para cada série/ano mantêm o enfoque das relações étnico-raciais. Os conteúdos tradicionais referentes à História Geral e das Américas, relativos, principalmente, aos séculos XIX, XX e XXI, foram distribuídos entre os três anos do segmento, tendo como parâmetro a divisão geográfica - África, América, Europa e Ásia.

No $1^{0}$ ano, as relações entre africanos, europeus e ameríndios são analisadas cronologicamente, partindo-se do século XVI até o XXI. As formações culturais dos povos africanos, afro-brasileiros e ameríndios recebem maior destaque (Objetivos de aprendizagem 4, 5, 6, 8,12, 14 e 16) ${ }^{5}$, mas a política se mantém na análise de reinos e impérios africanos e americanos, e no processo político vivenciado pelos povos africanos, entre os séculos XIX e XXI (Imperialismo, Descolonização e Pan-Africanismo). O escravismo colonial e as resistências à escravidão, também são enfocados, principalmente no tema "dimensão político-cidadã".

No $2^{\circ}$ ano, a temática enfoca a América. Apesar de aspectos culturais dos povos ameríndios serem elencados (Objetivo de aprendizagem 24), a tradicional história política retorna à pauta, abordando os processos políticos ocorridos nas Américas, a partir do século XV (Impérios americanos, colonização europeia, independências, conflitos armados - Guerra de Secessão, Guerra do Paraguai, Guerra do Pacífico -, formação de fronteiras, modelos políticos, processos revolucionários e ação do imperialismo).

\footnotetext{
5 A contagem dos objetivos de aprendizagem é reiniciada no início do Ensino Médio. (N. do A.).
} 
No 30 ano, o enfoque da narrativa histórica volta-se para a Europa e a Ásia. As relações entre os povos desses continentes e o Brasil são preferencialmente elencadas, como a Imigração Japonesa e a diáspora Judaica (Objetivo de aprendizagem 41), o Liberalismo (Objetivo de aprendizagem 44), os desdobramentos do Imperialismo (Objetivo de aprendizagem 45), as Guerras Mundiais (Objetivo de aprendizagem 46), as religiões presentes no Brasil (Objetivo de aprendizagem 47) e o papel dos movimentos sociais contemporâneos (Objetivo de aprendizagem 56). Salta aos olhos o fato de que a Europa é enfocada a partir de suas características mais negativas Imperialismo, exploração econômica, guerras, nazifascismo e stalinismo -, apesar do Objetivo de aprendizagem 53 estabelecer o reconhecimento das "presenças europeias e asiáticas nas histórias locais, valorizando-as e promovendo o respeito a essas diferenças" (BRASIL, 2015, p. 264). As culturas dos continentes europeu e asiático são abordadas, principalmente, em um objetivo de aprendizagem que trata da Antiguidade (55). Temas do século XX, como Guerra Fria, Revolução Chinesa, formação política, cultural e socioeconômica do Oriente Médio, e a crise da URSS, são colocados todos num mesmo Objetivo de aprendizagem (50) sob a forma de "discutir e argumentar criticamente sobre noções espaciais e temporais consagradas" - talvez uma maneira de contemplar tais temas, pelo menos no papel.

\section{Uma estrutura narrativa centrada nas relações étnico-raciais}

A construção da sociedade democrática na concepção da BNCC, passa, necessariamente, pela questão das relações étnico-raciais. Já na apresentação da proposta fica patente a preocupação de seus redatores com essa temática. Como exposto acima, a História promoveria, na concepção dos autores, o exercício da cidadania entre os educandos ao estimular o respeito às diferenças, sejam elas de cunho étnico-racial, ideológico, cultural ou religioso. O conceito de "cidadania" é associado, exclusivamente, à tolerância ao Outro, deixando-se de lado outros aspectos aos quais o termo se refere - participação política consciente, e assunção de direitos e deveres individuais, por exemplo. Se 
levarmos em conta, que as diferenças culturais e religiosas também se referem, no caso do Brasil, à temática das relações étnico-raciais ${ }^{6}$, podemos afirmar que a concepção de cidadania, constante na BNCC, denota a centralidade da questão étnico-racial para os formuladores da proposta, que, aparentemente, consideraram as demais acepções do conceito de "cidadania" como dadas, preocupando-se, apenas, em apontar a que tipo de cidadania se tinha em mente no momento de sua elaboração.

Nos objetivos de aprendizagem, propostos no percurso da Educação Básica, podemos observar a centralidade nas questões étnico-raciais. Elas dão a tônica da estrutura narrativa da BNCC. Podemos citar, como exemplo da importância dessa temática, vários objetivos de aprendizagem do eixo Dimensão Político-Cidadã7. Entre eles, encontram-se:

- Objetivo de aprendizagem 20 , do $2^{\circ}$ e do $3^{\circ}$ ano do Ensino Fundamental - "Identificar, vivenciar e valorizar as manifestações culturais constituídas historicamente na comunidade". (BRASIL, 2015, p. 245-6);

- Objetivo de aprendizagem 58, do $5^{\circ}$ ano do Ensino Fundamental "Identificar e valorizar suas origens em relação aos grupos que constituíram o povo Brasileiro" (BRASIL, 2015, p. 249);

- Objetivo de aprendizagem 93, do 70 ano do Ensino Fundamental "Reconhecer diferentes concepções e condições de vida de povos indígenas, colonizadores e migrantes europeus, povos africanos a afro-Brasileiros, relacionando-as às diversas formas de organização da vida e do trabalho, doas valores e necessidades de cada grupo, desnaturalizando preconceitos e estereótipos (BRASIL, 2015, p. 253);

- Objetivo de aprendizagem 36, do $2^{\circ}$ ano do Ensino Médio "Compreender e posicionar-se em relação aos racismos, preconceitos e discriminações referentes às pluralidades nas Américas nos séculos XIX, XX e XXI" (BRASIL, 2015, p. 262);

Os conteúdos elencados nos ensinos Fundamental e Médio, portanto, priorizam o estudo de problemáticas ligadas às relações raciais no Brasil,

6 Consideramos, aqui, as questões relativas às formações culturais e religiosas afro-brasileiras (festas, estilos musicais, vestimentas típicas, candomblé e umbanda, por exemplo). (N. do A.).

7 Vale ressaltar que a temática étnico-racial também se apresenta nos demais eixos. Os objetivos de aprendizagem do eixo Dimensão Político-Cidadã foram priorizados em nossa exemplificação devido às intenções específicas de formação cívica que o referido eixo procura promover. (N. do A.). 
deslocando o foco narrativo de uma perspectiva eurocêntrica para uma baseada na perspectiva brasileira, no caso, concebida como a dos povos dominados.

No afã de apresentar uma narração histórica alternativa e inclusiva para essas personagens, os criadores da BNCC simplesmente inverteram os papéis, relegando os europeus ao papel secundário - e muitas vezes de "vilões da História". Depreende-se dos conteúdos elencados, e da forma como foram dispostos, ao longo das séries da Educação Básica, iniciadas, principalmente, a partir do $6^{\circ}$ ano, que a História da América e do Brasil teve início na Pré-História americana, na qual viviam povos que passaram a ser escravizados pelos europeus ávidos pelo lucro. Encontramos um passado no qual os povos colonizados - cujas identidades são trabalhadas com maior acuidade, principalmente no 70 ano do Ensino Fundamental, e no 10 e 20 ano do Ensino Médio - foram explorados pelo europeu capitalista, cuja identidade cultural só vai ser analisada, com um pouco mais de atenção, no $3^{\circ}$ ano do Ensino Médio. Essa exploração foi marcada por grandes injustiças, mas estas foram combatidas através da resistência ativa dos povos dominados. No presente, vivemos em uma sociedade que se tornou democrática a partir da luta dos povos dominados no passado, como apontam os Objetivos de aprendizagem 138 e 139, do 90 ano, mas que ainda precisa ser depurada dos resquícios de exploração desse passado - o racismo, a desigualdade social, a falta de representatividade política -, tal é a intriga, constituinte da narrativa histórica, proposta pelo programa. As metodologias que ela suscita serão analisadas na próxima seção.

\section{Aspectos didático-metodológicos da BNCC}

Após a análise da estrutura narrativa, passamos aos aspectos didáticometodológicos constantes na proposta. Como vimos, a concepção de Ensino de História proposta pelos autores, cujos objetivos são orientados pela formação crítica dos educandos com vistas à prática cidadã consciente, voltada para os ideais democráticos, tem, na pesquisa e nos referenciais metodológicos do "ofício do Historiador", sua principal inovação. Tal concepção, a princípio, faz coro com as pesquisas mais atuais ligadas à Didática da História. Em nossa análise, 
focaremos em três categorias analíticas, constantes nas pesquisas sobre Ensino de História, que nos auxiliarão na compreensão da relação entre a narrativa histórica, constante na BNCC, e os objetivos de seus autores. Advertimos, ao leitor, que essas três categorias serão exploradas, isoladamente, apenas devido às exigências que uma explicação detalhada sobre suas características demanda. $\mathrm{Na}$ prática, elas operam de maneira conjunta e integrada, entre si e com a estrutura narrativa. Frisamos, também, que não há a pretensão de - nem o espaço para - esgotar, neste trabalho, todas as concepções elaboradas pelos pesquisadores sobre cada uma dessas categorias analíticas, sendo nossa análise focada nos aspectos suscitados pela BNCC, que podem ser observados a partir de tais categorias.

1) As finalidades do Ensino de História - A estrutura narrativa analisada na seção 2 - está diretamente ligada à concepção de Ensino de História adotada pelos elaboradores da BNCC, que a ajustaram às finalidades do que consideram como os objetivos do aprendizado da disciplina. Em primeiro lugar, para os autores, o estudo da História, através da "compreensão e problematização dos valores, dos saberes e dos fazeres de pessoas em variadas espacialidades e temporalidades, (...) favorece o exercício da cidadania, na medida em que estimula e promove o respeito às singularidades e às pluralidades étnico-raciais e culturais, à liberdade de pensamento e ação e às diferenças de credo e ideologia" (BRASIL, 2015, p. 240). Para tanto, defendem a problematização dos usos do passado como forma de desmistificar construções narrativas e identitárias veiculadas pelos meios de comunicação, a fim de possibilitar uma prática cidadã ancorada em ideais democráticos. Tal problematização passa, necessariamente, pelo desenvolvimento da pesquisa ancorada em "virtudes éticas", através da(s) qual/quais os (as) educandos (as) serão capazes de construir conhecimentos tendo como base suas próprias experiências e vivências (BRASIL, 2015, p. 241).

Os pesquisadores, consultados para elaboração deste artigo, são unânimes ao destacar o papel formativo do Ensino de História, no que tange ao desenvolvimento do pensamento crítico entre jovens, crianças e adultos. Joaquín Prats e Joan Santacana apontam como finalidades do ensino histórico 
análisis de la sociedad [...] para educar ciudadanos libres e con capacidad para discernir, por ellos mismos, sobre los problemas sociales de nuestro tempo. (PRATS, 2001, p. 114).

Peter Lee, com outras palavras, defende a mesma orientação ao afirmar que "uma pessoa que aprendeu alguma história (incluindo aqui tanto o conhecimento substantivo como o de segunda ordem) estará melhor equipada para lidar com o mundo do que ela estaria se não tivesse aprendido (LEE, 2011, p. 40). Além da conscientização progressiva dos fenômenos sociais aos quais estão sujeitos, os (as) educandos (as), através da aprendizagem histórica, são capazes de construir e problematizar suas próprias identidades (PRATS, 2001; RÜSEN, 2011, p. 44).

Nesse sentido, como vimos, a BNCC tende a seguir essa concepção de Ensino de História, ao focar a problemática étnico-racial brasileira e buscar, no estudo do passado, a formação (e a valorização) das identidades dos povos dominados pelos europeus. Entretanto, como aponta Lee (2011), para que tais objetivos sejam alcançados pelo Ensino de História, é necessário que o passado seja problematizado, o que nos leva ao segundo aspecto de nossa análise.

2) As relações entre passado, presente e futuro - a relação com o passado tem sido um ponto bastante destacado nas pesquisas sobre o Ensino de História. A maneira pela qual o passado é concebido, e abordado, nas salas de aula, tem relação direta na maneira pela qual os (as) educandos (as) se apropriam - ou não - dos conhecimentos e ferramentas próprios da disciplina, na medida em que as narrativas sobre o ocorrido em tal dimensão temporal correm o risco de assumir o caráter de "verdade", ou seja, do que "verdadeiramente aconteceu". Nossa experiência como professor, na Educação Básica, mostra o quanto esse caráter de "verdade", assumido pelo passado, está presente no imaginário dos (as) educandos (as) que, invariavelmente, elogiam aqueles professores (as) que "nos dizem como as coisas realmente aconteceram".

Ao justificar o Ensino de História nas escolas, Lee assinala que não podemos escapar do passado. O "[...] passado dá concreticidade aos nossos conceitos. Em muitas áreas do conhecimento o passado é a referência para o nosso conhecimento de regras e para a nossa capacidade de selecionar acontecimentos" (LEE, 2011, p. 20). Além disso, o autor aponta que "[...] as 
razões para as ações são referenciadas no passado" (LEE, 2011, p. 21). Isso significa que as ações tomadas no presente são baseadas nas experiências trazidas do passado, sejam elas de primeira ou de segunda mão, como é o caso do conhecimento histórico. Entretanto, o autor apresenta uma ressalva importantíssima: apenas a História apresenta uma narrativa racionalizada do passado. Para Lee "[...] sem história o passado serve meramente a interesses práticos" (LEE, 2011, p. 25). Isso significa que apenas o tipo de conhecimento, produzido pela ciência histórica, pode adentrar o passado de maneira que este se torne inteligível a partir de uma narrativa elaborada através de métodos próprios de racionalização, evitando - ou, pelo menos, minimizando - assim, a utilização abusiva do passado para fins políticos, ideológicos ou xenófobos. Prats nos adverte que

[...] el pasado es lo que lo ocurrió, la Historia es la investigación que explica y da coherencia a este pasado. Por ello, la Historia plantea cuestiones fundamentales sobre este pasado desde el presente, lo que no deja de ser una reflexión de gran contemporaneidad $\mathrm{y}$, por lo tanto, susceptible de compromiso (PRATS, 2001, p. 15).

Em outras palavras, o passado é inteligível, racionalmente, a partir de questões que a História como ciência estabelece desde o presente. Tais questões não surgem, isoladamente, da realidade social na qual estão inseridas, sendo "suscetíveis de compromisso" - ideológico, político, religioso, etc. Obviamente, o conhecimento histórico não está isento dessa influência, visto que é produzido por homens e mulheres inseridos no processo social. Mas, por ser um conhecimento científico, possui determinados parâmetros para ser produzido e validado e, além disso, pode ser produzido de maneiras variadas a partir de pressupostos teóricos e metodológicos variados, sendo que uma explicação histórica sobre determinado assunto, baseada neste ou naquele pressuposto, não exclui, necessariamente, outra sobre o mesmo tema que partiu de pressupostos diversos. Dessa forma, a postura científica de análise do passado, estabelecida pela História, admite variadas interpretações sobre essa instância temporal, evitando sua concepção como uma realidade fixa - o depositário da Verdade.

A concepção do passado influencia diretamente a forma pela qual os homens e as mulheres interpretam o seu presente e projetam o futuro. Koselleck 
(2006) define duas categorias históricas que nos remetem a essas instâncias temporais. Em relação ao passado, o historiador alemão criou o conceito de "espaço de experiência", no qual se concentram as diferentes temporalidades passadas e as experiências humanas acumuladas. É o passado tornado presente. Em relação ao futuro, Koselleck criou o conceito de "horizonte de expectativas", no qual as possibilidades abertas para a ação no futuro se encontram em estado de constante mutação. É o futuro tornado presente. $O$ autor frisa que não são categorias equivalentes, operando de maneiras diferentes na consciência humana. Mas as formas pelas quais essas categorias se relacionam subjetivamente determinam o que Koselleck vai chamar de "tempo histórico", ou seja, a forma pela qual os homens e mulheres racionalizam e inter-relacionam o passado, o presente e o futuro. Nas palavras do autor "[...] é a tensão entre experiência e expectativa que, de uma forma sempre diferente, suscita novas soluções, fazendo surgir o tempo histórico" (KOSELLECK, 2006, p. 313). Rüsen explica esse fenômeno através do conceito de consciência histórica, que consiste na combinação de um grupo coerente e complexo de operações mentais que "[...] contém a apreensão do passado regulada pela necessidade de entender o presente e de presumir o futuro" (RÜSEN, 2011, p. 36-7). Tais operações da consciência histórica "[...] proporcionam aos seres humanos segurança e autopersistência em face da mudança" (RÜSEN, 2011, p. 39), sendo, portanto, uma forma dos homens e mulheres construírem suas próprias identidades através dessa inter-relação entre o passado, o presente e o futuro.

Esta versão da BNCC apresenta a concepção de relação temporal proporcionada pela História e seus consequentes potenciais formativos. Os autores da proposta argumentam que

Uma questão central para o componente curricular História são os usos das representações sobre o passado, em sua interseção com a interpretação do presente e a construção de expectativas para o futuro. As análises históricas possibilitam assim, identificar e problematizar as figurações construídas por e sobre os sujeitos em suas diferentes noções de tempo, de sensibilidade e de ritmos. A reflexão sobre os usos do passado remete à memória e ao patrimônio e aos seus significados para os indivíduos nas suas relações com grupos, povos e sociedades. (BRASIL, 2015, p. 240). 
Assim, se levarmos em conta as concepções de relação temporal e de finalidade do Ensino de História no trecho destacado, e as aplicarmos à estrutura narrativa da disciplina na BNCC, verificamos que no espaço de experiência evocado encontra-se o passado marcado pela exploração e pela resistência dos povos colonizados. A partir desse espaço de experiência, o horizonte de expectativas, evocado pela BNCC, aflora com a promessa de uma sociedade, verdadeiramente democrática e multicultural, levada a cabo pela continuação das conquistas alcançadas pelos dominados, e que será possibilitada, entre outros fatores, pela conscientização de todos através do Ensino de História.

Entretanto, para que a estrutura narrativa implícita na BNCC e os objetivos declarados de sua proposta tenham a possibilidade de ser, efetivamente, apropriados pelos (as) educandos (as), é necessária uma estratégia de ensino que se adeque a tais propósitos. Isso nos leva à nossa terceira e última categoria analítica.

3) Metodologia de Ensino - a forma de trabalhar os conteúdos de História, proposta pelos pesquisadores consultados, apresenta vários pontos em comum. Entre eles, o principal é o papel da pesquisa na apreensão do cabedal teóricometodológico, por parte dos (as) educandos (as). Tal postura tem, como dissemos acima, profunda relação com a forma pela qual as relações das instâncias temporais e o Ensino de história são concebidos. Prats é bastante enfático ao assinalar a importância da pesquisa para o ensino, nos seguintes termos

\footnotetext{
Es importante que la Historia no sea para los escolares una verdad acabada, o una serie de datos y valoraciones que deben aprenderse de memoria. Es imprescindible que la Historia se trabaje en clase incorporando toda su coherencia interna y ofreciendo las claves para acercarse a su estructura como conocimiento científico del pasado. Es más interesante que los alumnos comprendan como podemos conseguir saber que lo pasó y como lo explicamos que la propia explicación de un hecho o periodo concreto del pasado. (PRATS, 2001, p. 21).
}

De acordo com o historiador espanhol, tal procedimento impede a concepção da História, por parte dos (as) educandos (as), como uma construção literária ou meramente cultural, pois evidencia o caráter científico desse tipo de conhecimento e, dessa forma, atende aos objetivos formativos propostos pelo 
Ensino de História. (PRATS, 2001, p. 21). Para tanto, Prats parte de pressupostos fornecidos pela didática, e dos elementos próprios do ofício do historiador, para apontar os objetivos de aprendizagem da disciplina História nas salas de aula: 1) aprender a formular hipóteses de trabalho - sempre formuladas a partir de uma questão do presente; 2) aprender a classificar as fontes históricas; 3) aprender a analisar as fontes; 4) aprender a avaliar criticamente as fontes e; 5) aprender a estabelecer laços de causalidade a fim de elaborar uma explicação histórica (PRATS, 2001, p. 24).

Jörn Rüsen (2011) parte do conceito de consciência histórica, cujas operações mentais constitutivas podem ser reduzidas a uma operação básica, a que ele nomeou narrativa histórica, para indicar os objetivos e a metodologia do Ensino de História. Para o historiador alemão "[...] o aprendizado histórico pode, portanto, ser compreendido como um processo mental de construção de sentido sobre a experiência do tempo através da narrativa histórica, na qual as competências para tal narrativa surgem e se desenvolvem" (RÜSEN, 2011, p. 43). Através do desenvolvimento dessa competência narrativa se dá o aprendizado histórico. Entretanto, como frisa Rüsen, não basta apenas a transmissão de conteúdos positivos, sem que haja a devida relevância de tais conteúdos para quem aprende. Nas palavras do autor

[...] o estímulo e a força pulsional do aprendizado histórico encontram-se nas necessidades de orientação de indivíduos agentes e pacientes, necessidades que surgem para tais indivíduos quando de desconcertantes experiências temporais. $O$ aprendizado histórico pode ser posto em andamento, portanto, somente a partir de experiências de ações relevantes do presente. (RÜSEN, 2011, p. 44).

Dessa forma, ao levarmos em consideração a posição de Rüsen, concluímos que a pesquisa histórica como forma de aprendizado deve, necessariamente, partir de questões próprias do (a) educando (a) pesquisador (a) para se tornar realmente efetiva.

Peter Lee (2004), partindo dos trabalhos de Rüsen, propõe que a orientação temporal, proporcionada pelo desenvolvimento do cabedal teóricometodológico a ser desenvolvido entre os (as) educandos (as), através do exercício da pesquisa histórica, deve necessariamente, estar acompanhando do 
que ele denominou Usable History Framework (UHF), ou Estrutura Utilizável do Passado. Lee o teoriza como um "quadro" ou estrutura do passado, construído pelos (as) educandos (as) ao longo de seu percurso escolar, que thes possibilite a sua manipulação, revisão, reorganização ou mesmo substituição por outro. Essa estrutura deve, necessariamente, comportar mais do que uma narrativa sobre o passado, de maneira que as várias narrativas sobre ele possam ser problematizadas, evitando, assim, a noção de "verdade histórica". Munidos desse quadro do passado, os (as) educandos (as) serão capazes de realizar, de maneira efetiva, a orientação no tempo característica da consciência histórica. Nas palavras do autor

Historical consciousness involves temporal orientation, a meaningful connection between past and future. If students are to have a meaningful connection of this kind, they will need some sort of framework of the past to form one element in the relationship ${ }^{8}$ (LEE, 2004, p. 8).

Ao conjunto dessas duas ferramentas - capacidade de compreender a forma pela qual a História é elaborada e a Estrutura Utilizável do Passado - Lee denominou Literacia Histórica. (LEE, 2006).

A BNCC, como vimos, apresenta a pesquisa como o principal elemento articulador dos conteúdos. Nos termos do documento

\begin{abstract}
A pesquisa é um princípio básico dos processos de construção de conhecimentos históricos, articulados aos outros componentes das Ciências Humanas e das demais áreas de conhecimento. Considera-se o/a estudante como agente da construção de conhecimentos, valorizando-se, assim, suas experiências individuais e coletivas. Nesse sentido, o exercício da crítica documental, nas suas diversas modalidades e linguagens, se constitui como procedimento articulador dos processos de construção de conhecimentos históricos. (BRASIL, 2015, p. 241)
\end{abstract}

Essa concepção não poderia estar mais de acordo com os pesquisadores elencados neste estudo. Os objetivos de aprendizagem, relacionados ao eixo "procedimentos de pesquisa", em todos os anos da Educação Básica,

\footnotetext{
8 "Consciência Histórica envolve orientação temporal, uma conexão significativa entre passado e futuro. Se os educandos (as) pretendem uma conexão significativa desse tipo, vão precisar de algum tipo de quadro do passado a fim de formar um dos elementos da relação". (Tradução livre do autor).
} 
estabelecem, a partir de uma complexidade progressiva ao longo da vida escolar dos (as) educandos (as), as formas de acesso, as maneiras de utilização e manipulação das diversas fontes, bem como os diferentes formatos de exposição dos resultados das pesquisas. Entretanto, apesar de apresentar a pesquisa como o "procedimento articulador dos processos de construção de conhecimentos históricos", ela já vêm, na BNCC, atrelada a conteúdos estabelecidos, de antemão, pelos próprios elaboradores da proposta.

Analisemos, a título de exemplo, o Objetivo de aprendizagem 79, do 70 ano: "Inferir, a partir de fontes diversas, o protagonismo de sujeitos em processos históricos no Brasil expressos em movimentos tais como a Confederação dos Tamoios (1556-1567), a Cabanagem (1835-1840) e a Balaiada (1838-1841) " (BRASIL, 2015, p. 252).

Encontramos, aqui, dois pontos inter-relacionados de atrito com as teorias expostas em nossas reflexões. Em primeiro lugar, o fato de que a pesquisa já parta de um resultado preestabelecido - o "protagonismo de sujeitos nos processos históricos" - implica, a princípio, retirar do (a) educando (a) pesquisador (a) a possibilidade de narrar os eventos de maneira diversa daquela estabelecida pela BNCC, inviabilizando a construção de narrativas múltiplas sobre o passado e mantendo a indesejada noção de "passado como verdade".

O segundo ponto de atrito diz respeito ao próprio protagonismo do (a) educando (a) pesquisador (a) na construção do conhecimento histórico, nos termos de Consciência Histórica, proposto por Rüsen. Se os eventos históricos (Tamoios, Cabanagem, Balaiada) e os objetivos a que estes eventos dão suporte (inferir o protagonismo de sujeitos nos processos históricos) já estão estabelecidos, de antemão, para cada série/ano de seu percurso escolar, é bastante plausível nos perguntarmos se o (a) educando (a), no 70 ano, se apropriará desse passado significativamente, caso não possua, absolutamente, nenhum interesse pessoal na questão nessa fase de sua vida.

Dessa forma, mesmo que se parta de uma pesquisa para pretensamente se alcançar a construção do conhecimento histórico, é lícito indagar se conteúdos preestabelecidos terão a capacidade de despertar o interesse dos (as) educandos (as) nessas fases específicas de suas vidas, e proporcionar uma aprendizagem histórica significativa. Uma possível resposta a essa pergunta pode ser obtida a 
partir dos estudos de pesquisadores franceses nas salas de aula daquele país. Guardadas as devidas proporções - relativas às diferenças entre Brasil e França - podemos, não obstante, encontrar as possíveis implicações práticas da metodologia de ensino proposta pela BNCC. Lautier, analisando as situações de aprendizagem de História nas salas de aula, nos adverte que

[...] enquanto que nos discursos pede-se aos alunos que produzam problemáticas, que participem de forma ativa da análise crítica dos documentos, nas práticas reais, a forma escolar de uma história fechada sobre o seu discurso do verdadeiro parece reconstituir-se muito rapidamente. (LAUTIER, 2011, p. 51).

\section{Considerações Finais}

Os elaboradores do componente História da BNCC, ao apresentarem suas concepções de ensino da disciplina, não apontam, em nenhum momento, uma base teórica sustentada por pesquisas em suas afirmações. Não há citações de autores/pesquisadores em suas ponderações, seja de historiadores ou de pedagogos. Tal fato, é sintomático da maneira pela qual a visão sobre o Ensino de História tem sido influenciada por uma postura não-científica da parte daqueles que deveriam propor novas maneiras de ensinar essa ciência. Mesmo que tal versão seja uma proposta a ser debatida pela população, é impensável que não haja uma base teórica sólida e declarada que a sustente, principalmente porque se pretende renovadora no ensino da disciplina. Esse fato demonstra que aspectos políticos, mais do que os teórico-metodológicos, foram decisivos na elaboração da proposta.

Gostaríamos de salientar, enfaticamente, que defendemos com muita seriedade a reformulação da atual narrativa histórica existente nos currículos e materiais didáticos escolares. Os povos ameríndios, africanos e afro-brasileiros estão sub-representados e, grande parte do preconceito e do racismo por trás da desigualdade social existente em nosso país, se deve a esse fato lamentável. Entretanto, essa reformulação, a nosso ver , não pode ocorrer em prejuízo das demais culturas que constituíram a identidade de nosso povo, como é o caso da europeia. 
O programa nacional de Ensino de História, proposto pela BNCC, se insere no contexto de uma reordenação dos poderes simbólicos que ocorre no Brasil. Essa reordenação, a despeito do vai-e-vem das conformações políticopartidárias, tem avançado no que tange à visibilidade dos grupos sociais marginalizados em nosso país, cujas identidades têm sido paulatinamente valorizadas com o objetivo de obter, para esses grupos, maior representatividade política e melhor inserção nos indicadores socioeconômicos.

Um dos principais baluartes para a manutenção hegemônica das elites brancas em nosso país, como vimos, é a própria concepção de identidade nacional, cuja narrativa, ora exclui, ora trata de maneira subordinada, não somente os indígenas e os negros, mas, também, o papel das mulheres e da população LGBT, na nossa conformação política, social, cultural e econômica. A narrativa histórica escolar tem um papel fundamental na construção dessa identidade, e é evidente que a proposta de História da BNCC não poderia fugir a essa influência.

Entretanto, se por um lado a assunção de uma perspectiva histórica que contemple os grupos marginalizados de nossa sociedade é um fator positivo, em outro aspecto, nos moldes estabelecidos pela BNCC, ela se torna tão problemática quanto a narrativa eurocêntrica. Nos conteúdos elencados, a participação da população europeia e de seus descendentes no Brasil, salvo nos casos dos imigrantes e da luta operária, aparece como a "vilã" da História, invertendo o sentido antes determinado pela versão eurocêntrica, mas proporcionando uma versão também parcial do processo histórico ao abrir a possibilidade para anacronismos, caso o branco seja sempre visto como o "vilão sem rosto" a partir de uma valoração ética situada no presente.

Além disso, podemos perceber uma tensão entre duas perspectivas narrativas significativas. De um lado, o apelo a uma narrativa nacional que contemple todos os grupos sociais do país. De outro, uma narrativa que estabeleça e valore as diferentes culturas locais e identidades de grupo, gênero, raça, etc., em pé de igualdade. Essa tensão, como vimos, foi resolvida pelos elaboradores da BNCC através do apelo à tradicional história política, cujos temas prevalecem no programa. Ao observarmos, com atenção, os conteúdos propostos, percebemos que foram elencados temas tradicionais do Ensino de 
História que se ajustam (ou podem ser adaptados, inclusive com novas nomenclaturas para os assuntos, como é o caso dos termos "Conquista" para se referir à chegada dos portugueses, "Golpe de Estado" para se referir à "Revolução" de 1930, etc.) à estrutura narrativa defendida pelos autores. Dessa forma, podemos estabelecer a seguinte indagação: a História nacional proposta para o ensino nas escolas possui uma limitação estrutural em sua narrativa advinda da própria maneira pela qual o Brasil se formou como nação - que a impediria de se libertar de uma abordagem prevalecentemente política e caminhar para uma narrativa verdadeiramente multicultural?

No plano metodológico do processo de ensino-aprendizagem, apesar de estabelecer algumas inovações como a centralidade da pesquisa, a forma pela qual se propõe o trabalho desses conteúdos em sala de aula, como constatamos, ainda privilegia algumas posturas, no mínimo, problemáticas. Isso se constata através da forma pela qual a pesquisa foi inserida na proposta da BNCC. Apesar de anunciar a pesquisa e o protagonismo do (a) educando (a) na construção dos conhecimentos históricos, o programa se desvia desse caminho ao propor pesquisas cujas respostas já estão dadas de antemão pelo próprio currículo. Isso implica na manutenção de uma narrativa histórica única e a centralidade do (a) professor (a) no estabelecimento de uma "verdade histórica". Tal situação pode suscitar dois problemas: em primeiro lugar, há perigo de os (as) educandos (as) se limitarem a fornecer as "respostas corretas" esperadas pelos (as) professores (as); em segundo, a possibilidade dos (as) próprios (as) professores (as), ao aplicarem as pesquisas, procurarem dirigir o processo ao máximo, evitando situações as quais não tenham controle dos resultados. Essa foi a conclusão de uma pesquisa realizada por Nicole Tutiaux-Gullion, nas salas de aula da França (TUTIAUX-GULLION, 2011), e nada impede que tal situação também ocorra no Brasil, ao se adotar os parâmetros metodológicos propostos pela BNCC.

Dessa forma o Ensino de História proposto, apesar da pretensa inovação, se mantém praticamente inalterado: é o professor que indica o assunto e é dele que sai toda a autoridade para validar as "respostas certas" - nada mais alheio à própria natureza do conhecimento histórico que se pretende ensinar, baseado na pluralidade de versões e identidades. Mantemos, portanto, esperança nas reformulações na proposta, a fim de que um Ensino de História, baseado no 
respeito dos interesses e identidades próprias de cada educando (a), em sua procura por orientação temporal, seja possível, a fim de se construir uma sociedade, verdadeiramente, plural, composta por indivíduos intelectualmente autônomos.

\section{Referências}

BRASIL. Base nacional comum curricular. Brasília: Ministério da Educação, 2015.

DOMINGUES, Petrônio. Movimento negro brasileiro: alguns apontamentos históricos. Tempo, Niterói: EDUFF, v. 12, n. 23, p. 100-122, 2007.

GOHN, Maria da Glória. Teoria dos movimentos sociais: paradigmas clássicos e contemporâneos. 7. ed. São Paulo: Loyola, 2008.

GUIMARÃES, Antonio S. A. Racismo e antirracismo no Brasil. São Paulo: Editora 34, 2009.

HALL, Stuart. A identidade cultural na pós-modernidade. Rio de Janeiro: DP\&A, 2006.

HALL, Stuart. Da diáspora: identidades e mediações culturais. Belo Horizonte: UFMG, 2013.

KOSELLECK, Reihart. Futuro passado: contribuição à semântica dos tempos históricos. Rio de Janeiro: Contraponto: PUC-Rio, 2006.

LAUTIER, Nicole. Os saberes históricos em situação escolar: circulação, transformação e adaptação. Educação e Realidade, Porto Alegre, v. 36, n. 1, p. 39-58, jan./abr. 2011.

LEE, Peter. Walking backwards into tomorrow: historical consciousness and understanding history. International Journal of Historical Learning, Teaching and Research, Exeter, v. 4, n. 1, p. 1 -46, Jan. 2004.

LEE, Peter. Em direção a um conceito de literacia histórica. Educar em Revista, Curitiba, n. esp., p. 1-14, 2006.

LEE, Peter. Por que aprender História? Educar em Revista, Curitiba, n. 42, p. 1942, dez. 2011.

MARTINS, Mônica. Carta crítica da Anpuh-Rio à composição do componente curricular história na base nacional comum curricular. Rio de Janeiro: ANPUH-RJ, 2015. Disponível em <http://rj.anpuh.org/arquivo/download?ID_ARQUIVO=60972>. Acesso em: 12 jan. 2016. 
ORTIZ, Renato. Cultura brasileira e identidade nacional. São Paulo: Brasiliense, 2006.

PRATS, Joaquín. Enseñar historia: notas para una didáctica renovadora. Mérida: Junta de Extremadura, 2001.

RÜSEN, Jörn. Jörn Rüsen e o ensino de história. Curitiba: UFPR, 2011.

SKIDMORE, Thomas E. Uma história do Brasil. Rio de Janeiro: Paz e Terra, 1978.

SOUZA, Jessé. A tolice da inteligência brasileira. São Paulo: LeYa, 2015.

TUTIAUX-GILLON, Nicole. O paradoxo francês: cultura histórica significativa e didática da história incerta. Educação e Realidade, Porto Alegre, v. 36, n. 1, p. 15-37, jan./abr. 2011. 